\title{
Structural correlations among aromatic azine derivatives
}

\author{
Theunis G.D. van Schalkwyk and Alistair M. Stephen \\ Department of Chemistry, University of Cape Town, Rondebosch 7701, South Africa \\ E-mail:stepham@science.uct.ac.za
}

(received 19 Jan 05; accepted 22 Mar 05; published on the web 20 Apr 05)

\begin{abstract}
This paper is a sequel to the ARKIVOC publication [2002 (iii) 103-111] describing the spontaneous conversion of the methochloride (A) of salicylaldazine to the azine (B), which is considered to take place via the oxidation of an $N$-alkylhydrazone. X-Ray crystallographic aspects of (A), (B) and three related compounds are presented, and a survey given of the conformations of a number of derivatives of the parent compound benzaldazine. Three categories of structure are discerned, one essentially planar, another twisted as a consequence of steric interactions in the neighborhood of the azine system, and a third group having further distinctive features including extreme deviations from planarity.
\end{abstract}

Keywords: Aromatic azines, conformation, configuration, X-ray crystallography

\section{Introduction}

The set of aromatic azines and their derivatives described is of interest on account of the facile de-N-alkylation of the methochlorides (and related compounds) 1,cf.2, and their interesting physical properties, but it is the conformational aspect that is presently under review. The literature has been scanned in order to make structural comparisons among substituted benzalazines, as has formerly been done eg. by Glaser and co-workers ${ }^{3}$ and others ${ }^{\text {cf.4 }}{ }^{\text {; these }}$ compounds have been grouped according to the degree of distortion brought about by interactions within the azine system.

\section{Results and Discussion}

Prismatic yellow crystals of salicylaldazine methochloride (A) from methanol or other lowmolecular weight alcohols, were usually threaded with needles of salicylaldazine (B), and furthermore the crystals were twinned; accordingly the structure determined by x-ray diffraction using direct methods of phasing ${ }^{4}$ did not have an R-factor of $<0.145$. However, the $\mathrm{Z}, E$ 
configuration is unequivocal, by contrast with the expected $E, E$ of $(\mathbf{B})$. The near-planar structure of (A) and the juxtaposition of the ring planes of the molecules are described in the Experimental section, which gives also the crystal features of compounds (C)-(E). The structure of $\mathbf{B}$ was solved by direct methods ${ }^{4}$, final R-factor 0.041 (cf. Ref. 10). The methochloride of $p$ hydroxybenzaldehyde azine (C) and the azine (D) itself, likewise have the $Z, E$ and $E, E$ configurations respectively. Crystalline acetophenone azine (E), from which a metho-derivative could not be prepared, showed the $E, E$ configuration, but was not centro-symmetric, and the principal residues (aromatic rings) tended to be orthogonal (cf. Ref. 15).

A CSD search, undertaken to find what structural variations existed among aromatic azines in general, yielded over 200 examples, from which 46 structures with formulae related to (A) (E) were selected for comparison purposes. Eleven contained the system $[\mathrm{ArCH}=\mathrm{N}-]_{2}$, and a large set $[\mathrm{ArCMe}=\mathrm{N}-]_{2}$; some were related compounds with differently-substituted aromatic rings, and others were of the form $[\mathrm{ArCH}=\mathrm{N}-\mathrm{N}=\mathrm{CMeAr}$ ']. Seven examples contained other groups $\mathrm{X}$, in the system $[\mathrm{ArCX}=\mathrm{N}-]_{2}$. The effects of steric hindrance on the preferred $E, E$ structures are clearly seen; only one apart from those of (A) and (C) has the $Z, E$ configuration. The most marked conformational changes result from substitution of various bulky groups for $\mathrm{H}$ on the azine carbon atoms; bizarre 3-dimensional structures develop where there is exceptional steric hindrance. The essential molecular formula showing torsional angles $\mathrm{T} 1$ to $\mathrm{T} 5$ and bond angles A1 and A2 is given below as Diagram 1, and should be used in conjunction with a model.

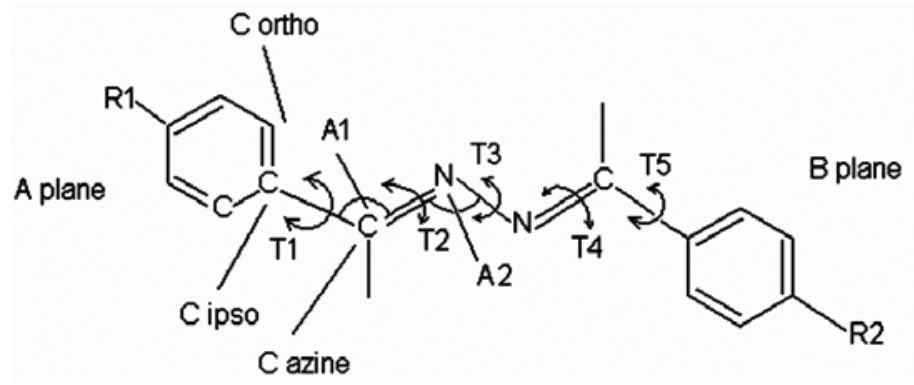

Diagram 1. Each molecule has two aromatic ring planes, designated A and B. Between lies a chain of four atoms that controls the conformation.

Of the torsional angles, if $\mathrm{T} 3$ is $180^{\circ}$ as in the diagram, conjugation of two halves (A and B) of the azine molecule is at a maximum, i.e. may cross the $\mathrm{N}-\mathrm{N}$ barrier $^{3}$, with the $\mathrm{N}$ non-bonded electron pairs not being implicated. Values forT2 and $\mathrm{T} 4$ about the $\mathrm{C}=\mathrm{N}$ double bond are relatively constant, except for some of the $[\mathrm{ArCX}=\mathrm{N}-]_{2}$ examples. Lack of conjugation of $\mathrm{C}=\mathrm{N}$ with the aromatic pi-systems is suggested by the $\mathrm{T} 1$ and $\mathrm{T} 2$ values, which are often large. The relationship between the planes A and B follows from the magnitude and sign of T1 and of T2, and is influenced in $c a .15$ examples by significant values of T3.

Analysis of molecular conformations (NB for $E, E$ T3 is $180^{\circ}$, but in order to demonstrate deviations from planarity, the $E, E$ angle $\mathrm{T} 3$ is recorded as $0^{\circ}$, and deviations as + or - , so to be 
compatible with T1 andT5. This applies also to the T2 and T4 values where tabulated. For this reason the Greek tau symbol is not used).

\section{Set (i). Molecules $[\mathrm{ArCH}=\mathbf{N}-]_{2}$}

The prototype 1 (benzalazine) is, but for a $2.4^{\circ}$ rotation of the ring planes, a planar molecule overall. $\mathbf{2}$ shows the effect of monoprotonation of $\mathbf{1}$ at an $\mathrm{N}$ atom, which gives a T3 value of $5^{\circ}$, in addition to a $7^{\circ}$ angle between the benzene ring planes. The twist of the benzene rings relative to one another enlarges to nearly $24^{\circ}$ in the $p, p^{\prime}$,-dibromo derivative 3 , T3 here being restored to zero (an antiperiplanar arrangement of $\mathrm{N}=\mathrm{C}$ groups). Overall planarity of structure characterizes 4 , in spite of the seven-carbon terminal chains, and similarly the mixed $p$-cyano/ $p$-methoxyl derivative 5 , apart from the $7^{\circ}$ angle between the benzene ring planes. 6 has been described in detail above (as $\mathbf{D}$ ), exhibiting a considerable $\left(14^{\circ}\right)$ T3 and inter-benzene plane angle $\left(17^{\circ}\right) .7$ is the important example described in full above (B). There is virtual overall planarity, and the structure uniquely allows for strong H-bonding between ortho-OH groups and $\mathrm{N}$ atoms. 8, the Me ether corresponding to 6 (D), has a $4^{\circ}$ twist associated with the benzene rings. 9 (4-pyridinium rings instead of phenyl) is unexceptionally planar; $\mathbf{1 0}$ and $\mathbf{1 1}$ show $11^{\circ}$ and $7^{\circ}$, conrotatory, benzene-ring twists, and necessarily out-of-plane situations for $\mathrm{F}$ substituents in the $\mathrm{CH}_{2} \mathrm{~F}$ and $\mathrm{CF}_{3}$ ethers respectively.

The average $\mathrm{N}-\mathrm{N}$ bond length (D3) for examples 1-11, all of which are $E, E$ and show minimal effects on the azine system by the $p$-,p-substituents, is $1.409+-0.003 \AA$, whereas the universal average for $\mathrm{N}-\mathrm{N}$ is $1.383-1.403$, and for $\mathrm{N}=\mathrm{N} 1.255$. The variation is within uncertainty limits, except for 8 and 9 (N-N 1.418 and 1.400 respectively), the termini of which are the most electronreleasing and electron-attracting. Details in Table 1. In this and subsequent tables centrosymmetric structures are starred. Concerning T3, the central rotational parmeter, the policy was adopted in drawing up the tables that follow to express the tortional angle as a deviation from the $180^{\circ}$ which allows maximum conjugation (because of coplanarity) of the $\mathrm{C}=\mathrm{N}$ double bonds. This is based on recognition of the fact that the sign of $\mathrm{T} 3$ is assigned arbitrarily in the publications cited; signs of the other torsion angles are coherent with the decision made for T3 in particular cases. The signs for the angles recorded here (excepting T3) are as taken from the literature, and values are throughout rounded off to integral numbers. 
Set (ii). Molecules $[\mathrm{ArCMe}=\mathrm{N}-]_{2}$

Table 1. Asterisks following molecule numbers indicate centrosymmetric

\begin{tabular}{cccccccccc}
\hline Molecule $^{\text {Ref }}$ & $\mathrm{N}-\mathrm{N} / \AA$ & $\mathrm{T} 3$ & $\mathrm{~T} 1$ & $\mathrm{~T} 5$ & Remarks & $\mathrm{R} 1$ & $\mathrm{R} 2$ & $\mathrm{~A} 1 /^{\circ}$ & $\mathrm{A}^{\circ}{ }^{\circ}$ \\
\hline $\mathbf{1}^{*}$ & 1.412 & 0 & 2 & -2 & & $\mathrm{H}$ & $\mathrm{H}$ & 122 & 113 \\
$\mathbf{2}^{6}$ & 1.402 & 5 & 4 & -3 & $\mathrm{NH}^{+}$(cf.A) & $\mathrm{H}$ & $\mathrm{H}$ & 125 & 120 \\
$\mathbf{3}^{7}$ & 1.408 & 0 & 21 & -2 & & $\mathrm{Br}$ & $\mathrm{Br}$ & 119 & 111 \\
$\mathbf{4}^{*}$ & 1.406 & 0 & -4 & 4 & & $\mathrm{C}_{6} \mathrm{H}_{13} \mathrm{O}$ & $\mathrm{C}_{6} \mathrm{H}_{13} \mathrm{O}$ & 121 & 111 \\
$\mathbf{5}^{9}$ & 1.406 & -4 & -2 & 4 & $a$ & $\mathrm{MeO}$ & $\mathrm{CN}$ & 121 & 112 \\
$\mathbf{6}^{4}$ & 1.412 & -14 & -4 & 13 & $=\mathbf{D}$ & $\mathrm{HO}$ & $\mathrm{HO}$ & 124 & 113 \\
$\mathbf{7}^{10}$ & 1.410 & 0 & -3 & 3 & $=\mathbf{B}$ & $\mathrm{H}$ & $\mathrm{H}$ & 121 & 113 \\
$\mathbf{8}^{8}$ & 1.418 & 1 & 4 & 0 & $b$ & $\mathrm{MeO}$ & $\mathrm{MeO}$ & 121 & 111 \\
$\mathbf{9}^{11}$ & 1.400 & 0 & - & - & $b c$ & $\mathrm{NH}^{+}$ & $\mathrm{NH}^{+}$ & 119 & 112 \\
$\mathbf{1 0}^{*}{ }^{12}$ & 1.413 & 0 & -11 & 11 & & $\mathrm{~F}_{2} \mathrm{CHO}$ & $\mathrm{F}_{2} \mathrm{CHO}$ & 121 & 115 \\
$\mathbf{1 1}^{* 13}$ & 1.417 & 0 & 7 & -7 & & $\mathrm{~F}_{3} \mathrm{CO}$ & $\mathrm{F}_{3} \mathrm{CO}$ & 121 & 122 \\
\hline
\end{tabular}

$a$ Contrast 5 with 29, which has $\mathrm{C}_{\text {azine }} \mathrm{Me}$; $\mathrm{T} 3$ is $62^{\circ}$ for $\mathbf{2 9}$, and there are other distortions.

$b$ Largest and smallest $\mathrm{N}-\mathrm{N}$ bond lengths.

$c \mathrm{CH}$ in $p$ position replaced by $\mathrm{NH}^{+}$.

Table 2. Asterisks following molecule numbers indicate centrosymmetric

\begin{tabular}{cccccccccc}
\hline Molecule $^{\text {Ref }}$ & $\mathrm{N}-\mathrm{N} / \AA$ & $\mathrm{T} 3$ & $\mathrm{~T} 1$ & $\mathrm{~T} 5$ & Remarks & $\mathrm{R} 1$ & $\mathrm{R} 2$ & $\mathrm{~A} 1 /^{\circ}$ & $\mathrm{A}^{\prime} /^{\circ}$ \\
\hline $\mathbf{1 2}^{* 14}$ & 1.390 & 0 & -5 & 5 & $a$ & $o$-HO $p$-EtO & $o$-HO $p$-EtO & 117 & 116 \\
$\mathbf{1 3}^{* 15}$ & 1.397 & 0 & -1 & 1 & & $\mathrm{CN}$ & $\mathrm{CN}$ & 115 & 114 \\
$\mathbf{1 4}^{* 16}$ & 1.404 & 0 & 12 & -12 & & $\mathrm{CO}_{2} \mathrm{Et}$ & $\mathrm{CO}_{2} \mathrm{Et}$ & 116 & 114 \\
$\mathbf{1 5}^{* 16}$ & 1.395 & 0 & 3 & -3 & & $\mathrm{NHAc}$ & $\mathrm{NHAc}^{16}$ & 115 & 114 \\
$\mathbf{1 6}^{16}$ & 1.402 & 0 & -14 & 14 & & $\mathrm{NMe}_{2}$ & $\mathrm{NMe}_{2}$ & 117 & 114 \\
$\mathbf{1 7}^{17}$ & 1.402 & 0 & 11 & -11 & $b$ & $\mathrm{OCOEt}$ & $\mathrm{OCOEt}$ & 114 & 114 \\
$\mathbf{1 8}^{16}$ & 1.409 & 0 & -9 & 11 & & $\mathrm{MeO}$ & $\mathrm{MeO}$ & 116 & 114 \\
$\mathbf{1 9}^{18}$ & 1.405 & 0 & -24 & 24 & $c$ & $\mathrm{Me}$ & $\mathrm{Me}$ & 116 & 114 \\
\hline
\end{tabular}

$a$ Special case (cf.7) having ortho-HO, H-bonded to $\mathrm{N}$, for each aryl ring. This promotes planarity of the azine system.

$b$ One of two independent sets of molecules.

$c$ Having the same formula as $\mathbf{2 6}$, which is not centrosymmetric.

This group of compounds [ArCMe $=\mathrm{N}-]_{-2}$ is markedly different structurally from that described above as Set (i), in that steric hindrance causes distortion about the N-N bond, with the result that T3 tends in some of the cases to be much larger, and the general form of the molecule approximates rather to an orthogonal than a planar structure. There is, however, an observable gradation in this 
trend. 12 is a special case, being almost planar, but this no doubt follows from the strong H-bonding of the $o$-HO substituent to $\mathrm{N}$ as observed in (7). 13 and $\mathbf{1 4}$ are relatively flat molecules, perhaps due to of the effect of electron-withdrawing $p$-substituents which embody $\mathrm{C}-\mathrm{N}$ triple bonds and trigonal C, respectively (and influence stacking). In 14 the opposite signs of T1 and T5 result in the aromatic rings being twisted conrotationally with respect to the azine system, losing conjugation, which however is gained by incorporation of the unsaturated substituent moieties. Compounds $\mathbf{1 5}$ to $\mathbf{1 9}$ all contain a planar system $\mathrm{C}=\mathrm{N}-\mathrm{N}=\mathrm{C}$, but of these $\mathbf{1 6}$ to $\mathbf{1 9}$ show marked twisting (T1 and T5: $-24^{\circ}$, $+24^{\circ}$ for 19).

The average bond length N-N for $\mathbf{1 2}$ to $\mathbf{1 9}$ (all centrosymmetric molecules) is $1.401 \AA$, with a large scatter (1.390 to 1.409), these being values for $\mathbf{1 2}$ (the special case; see above) and $\mathbf{1 8}$ (end groups electron-releasing, as for Set (i). If anything this shows that Me replacing $\mathrm{H}$ in the azine moiety, releasing electrons on to $\mathrm{N}$, increases the charge and shortens the N-N bond. Another way of regarding the effect of the methyl group is to assume hyperconjugation (the old "no-bond resonance") with $\mathrm{H}_{2} \mathrm{C}=\mathrm{N}$ imparting some double-bond character to $\mathrm{N}-\mathrm{N}$. Contrariwise, the electron density enhancement by conjugation of $p$-RO might lengthen N-N. More on the effects of electronegativities of $p$-groups is given below (see Table 3).

For 20 the twist about N-N is large, and disrotation of the benzene rings is large as well; in the case of $\mathbf{2 1}$ one ring only is skewed, in spite of the p- substituents being the same. The structural prototype of Set (ii) is acetophenone azine 22, equal to (E), which has T3 $41^{\circ}$ and one benzene ring coplanar with $\mathrm{C}=\mathrm{N}$, but not the other ring with respect to the adjacent $\mathrm{C}=\mathrm{N}$, the latter being (T5) $20^{\circ}$ out of plane. Thus for the two separate halves of the molecule conjugation is preserved in one but not in the other. 
Table 3

\begin{tabular}{|c|c|c|c|c|c|c|c|c|c|}
\hline $\begin{array}{c}\text { Molecule } \\
\text { Ref }\end{array}$ & CSD Code & $\mathrm{N}-\mathrm{N} / \AA \AA$ & T3 & $\mathrm{T} 1$ & T5 & Remarks & R1 & R2 & $\begin{array}{c}\mathrm{T} 2+ \\
\mathrm{T} 4\end{array}$ \\
\hline $20^{19}$ & BITTIH & 1.419 & -31.6 & 18.6 & 12.8 & $a$ & $\mathrm{HO}$ & $\mathrm{HO}$ & -6.9 \\
\hline $21^{16}$ & ZEHJUR & 1.398 & -28 & 1.2 & 14.1 & & $\mathrm{NO}_{2}$ & $\mathrm{NO}_{2}$ & -5.4 \\
\hline $22^{15}$ & LIKHIW & 1.403 & 41.3 & 0.4 & 19.7 & $(=\mathbf{E})$ & $\mathrm{H}$ & $\mathrm{H}$ & 2.9 \\
\hline $23^{15}$ & LIKHOC & 1.396 & -42 & 1.9 & -10.6 & $b$ & $\mathrm{~F}$ & $\mathrm{~F}$ & -4.9 \\
\hline $24^{15}$ & LIKHUI & 1.398 & -45.3 & -29.3 & -30.5 & $b$ & $\mathrm{Cl}$ & $\mathrm{Cl}$ & -7.8 \\
\hline $25^{15}$ & LIKJEU & 1.383 & -55.4 & -27.3 & -21 & $b$ & $\mathrm{Br}$ & $\mathrm{Br}$ & -9.6 \\
\hline $26^{18}$ & PIYYAX & 1.407 & 37.2 & -0.5 & 19.9 & (cf. E) & $\mathrm{Me}$ & Me & 8.1 \\
\hline $27^{16}$ & ZEHJIF & 1.409 & -48.9 & -15.1 & -0.2 & $a$ & $\mathrm{NH}_{2}$ & $\mathrm{NH}_{2}$ & -3.3 \\
\hline $28^{20}$ & VIJVOS & 1.406 & 40.7 & 13.9 & 6.3 & $c$ & $\begin{array}{c}\mathrm{O}\left(\mathrm{CH}_{2}\right)_{5} \\
{ }_{-}-\mathrm{CO}_{2} \mathrm{H}\end{array}$ & $\begin{array}{c}\mathrm{O}\left(\mathrm{CH}_{2}\right)_{5} \\
{ }_{-} \mathrm{CO}_{2} \mathrm{H}\end{array}$ & 1.6 \\
\hline $29^{21}$ & ZIFCAS & 1.390 & 62.1 & 16.3 & 14.1 & $d$ & $\mathrm{CN}$ & $\mathrm{OMe}$ & 7.2 \\
\hline $30^{22}$ & BIWZIQ & 1.414 & 56.4 & 29.6 & -8.4 & $a$ & $\mathrm{~F}$ & $\mathrm{NH}_{2}$ & 2.8 \\
\hline $31^{21}$ & ZIFBUL & 1.374 & -43.9 & -17.9 & -3.1 & $e$ & $\mathrm{Br}$ & OMe & -2.7 \\
\hline $32^{21}$ & ZIFCEW & 1.396 & -45.9 & -1.4 & -5.2 & $f$ & $\mathrm{NO}_{2}$ & OMe & -9.1 \\
\hline
\end{tabular}

$a$ Very high N-N; cf. 6, Table 1.

$b$ The torsion angles T3 follow a pattern reflecting the various electronegativities of R1= R2, as interpreted by Glaser and his co-workers (Ref. 15). Data for the I,I derivative given in Ref.23.

$c$ For 28 complex (identical) end groups impart irregular profile.

$d$ T3 exceptionally high. T1 and T5 nearly equal although the conjugative effects of electron-releasing OMe and electron-attracting $\mathrm{CN}$ differ.

$e$ One of two independent sets of molecules, showing very different parameters. One only is quoted. T2 and T4 are small and nearly equal.

$f$ Although 32 twisted about N-N, exterior groups R1 and R2 highly conjugated with aryl rings.

\section{Set (iii). Molecules [ArCMe $=\mathrm{N}-]_{2}$, all non-centrosymmetric}

The group that follows, $\mathbf{2 0}$ to $\mathbf{3 2}$ forms a relatively coherent set and because of many resemblances to $22(=\mathbf{E})$ are tabulated together, with comments as footnotes. The two halves of each azine are independent (T3 finite and large), and although the substitution patterns from $\mathbf{2 0}$ to $\mathbf{2 8}$ are the same in each molecule, the molecular conformations (T1 vs T5) are different. R1 and R2 differ in 29 to 32. Inter-plane angles for pairs of aryl rings are very large for 22 to $\mathbf{3 2}$. Table 3 includes first decimal, and summation of the torsion angles (including T2 and T4 which indicate twisting about double bonds) gives a value for the inter-plane angle in each case. These values agree well with those measured on the screen, when the molecule is appropriately displayed. Code letters are tabulated for $\mathbf{2 0}$ to 32, and certain molecules are formulated in Diagram 1a. 


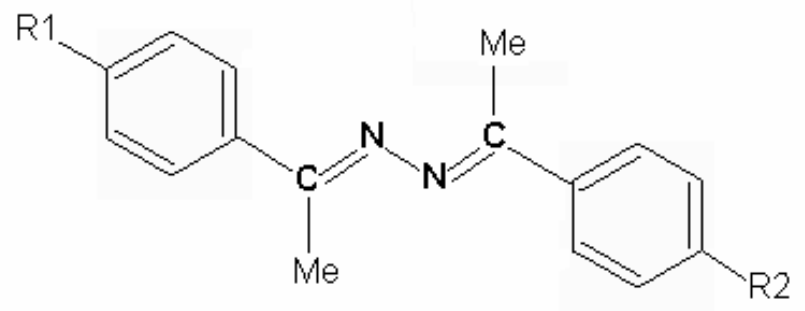

\section{Diagram 1a}

$$
\begin{array}{ll}
28 & \mathrm{R} 1=\mathrm{R} 2=\mathrm{O}\left(\mathrm{CH}_{2}\right)_{5} \mathrm{COOH} \\
30 & \mathrm{R} 1=\mathrm{F}, \mathrm{R} 2=\mathrm{NH}_{2} \\
31 & \mathrm{R} 1=\mathrm{Br}, \mathrm{R} 2=\mathrm{OMe} \\
32 & \mathrm{R} 1=\mathrm{NO}_{2}, \mathrm{R} 2=\mathrm{OMe}
\end{array}
$$

\begin{tabular}{|c|c|c|c|c|c|c|c|c|c|}
\hline Molecule ${ }^{\text {Ref }}$ & $\mathrm{N}-\mathrm{N} / \AA$ & T3 & $\mathrm{T} 1$ & T5 & Remarks & $\mathrm{R} 1$ & $\mathrm{R} 2$ & $\mathrm{~A} 1 /^{\circ}$ & $\begin{array}{c}\mathrm{A} 2 / \\
\mathrm{o}\end{array}$ \\
\hline $33^{9}$ & 1.405 & -4 & 12 & -2 & $a b$ & $\mathrm{MeO}$ & OCN & 116 & 116 \\
\hline $34^{24}$ & 1.405 & 18 & -11 & -8 & $a$ & $\mathrm{NO}_{2}$ & $\mathrm{NMe}_{2}$ & 121 & 112 \\
\hline $35^{+9}$ & 1.400 & 29 & 20 & 6 & $a$ & $\mathrm{CN}$ & $\mathrm{OMe}$ & 121 & 114 \\
\hline $36^{* 25}$ & 1.396 & 0 & -5 & 5 & $\mathrm{C}_{\text {azine }} \mathrm{CN}$ & $\mathrm{H}$ & $\mathrm{H}$ & 121 & 113 \\
\hline $37 * 26$ & 1.407 & 0 & 6 & -6 & $\mathrm{C}_{\mathrm{az}}\left(\mathrm{CO}_{2} \mathrm{Me}\right)$ & $\mathrm{H}$ & $\mathrm{H}$ & 121 & 112 \\
\hline $38 * 27$ & 1.418 & 0 & -6 & 6 & $\mathrm{C}_{\mathrm{az}}\left(\mathrm{CO}_{2} \mathrm{Et}\right)$ & $\mathrm{H}$ & $\mathrm{H}$ & 121 & 112 \\
\hline $39^{28}$ & 1.410 & $c$ & $c$ & $c$ & $\mathrm{C}_{\mathrm{az}} \mathrm{H}, \mathrm{NH}_{2}$ & $\mathrm{MeO}$ & $d$ & 123 & 114 \\
\hline $40^{29}$ & 1.425 & -6 & $c$ & $c$ & $\mathrm{C}_{\mathrm{az}} \mathrm{NH}_{2}, \mathrm{NH}_{2}$ & $e$ & $e$ & 117 & 112 \\
\hline
\end{tabular}

\section{Set (iv). Special set: various azine systems}

Table 4. Asterisks following molecule numbers indicate centrosymmetric

+ One of two independent sets of molecules.

$a$ CazMe, CazH system in 33; and CazH, CazMe in $\mathbf{3 4}$ and 35.

$b$ One ring plane skewed, minimal T3. This is one of four independent sets of molecules.

$c$ Figures not available, but values are small.

$d$ 2-Thiopyrazolyl in place of phenyl ring. A1 not=corresponding A4, A2 not=corresponding A3.

$e o$-Pyridyl in place of each phenyl ring.

The structures $\mathbf{3 3}$ to $\mathbf{4 0}$ form a sub-set resembling those of set (i), only $\mathbf{3 5}$ having the aryl rings twisted to a large extent, but here the variety of sustituents on the azine carbon results in unusual features. The $[\mathrm{PhC}(\mathrm{CN})=\mathrm{N}-]_{-2}$ system of $\mathbf{3 6}$ shows a conrotatory twist of $5^{\circ}$ for each aryl ring, but $\mathrm{N}-\mathrm{N}(1.396 \AA)$ is close to that of the distantly related molecule $\mathbf{1 3 .} 37$ and $\mathbf{3 8}$ are carboxylate esters corresponding to the nitrile $\mathbf{3 6}$, and are essentially planar, but the large ester groups lie orthogonally 
to the plane; the phenyl rings are each twisted by $6^{\circ}$ in a conrotatory mode. $\mathbf{3 9}$ and $\mathbf{4 0}$ are unique with primary amino groups on azine carbons, two such in $\mathbf{4 0}$. For $\mathbf{4 0} \mathrm{T} 3$ is $6^{\circ}$ and the $o$-pyridyl rings are twisted with respect to each other. Certain of these molecules are formulated in Diagram 1b.

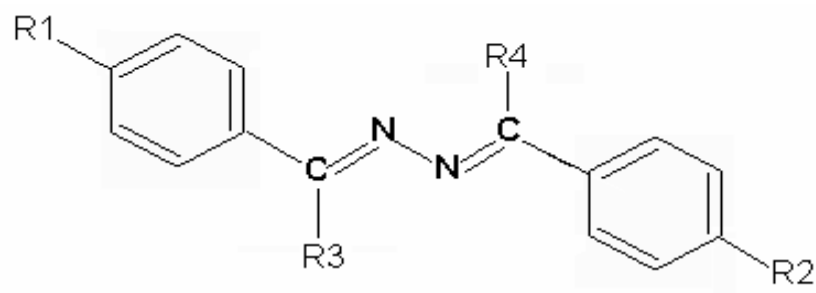

$$
\begin{array}{ll}
33 & \mathrm{R} 1=\mathrm{OMe}, \mathrm{R} 2=\mathrm{OCN}, \mathrm{R} 3=\mathrm{Me}, \mathrm{R} 4=\mathrm{H} \\
34 & \mathrm{R} 1=\mathrm{NMe}_{2}, \mathrm{R} 2=\mathrm{NO}_{2}, \mathrm{R} 3=\mathrm{H}, \mathrm{R} 4=\mathrm{Me} \\
35 & \mathrm{R} 1=\mathrm{OMe}, \mathrm{R} 2=\mathrm{CN}, \mathrm{R} 3=\mathrm{H}, \mathrm{R} 4=\mathrm{Me} \\
39 & \mathrm{R} 1=\mathrm{OMe}, \mathrm{R} 2=\mathrm{N}, \mathrm{R} 3=\mathrm{H}, \mathrm{R} 4=\mathrm{NH}_{2}
\end{array}
$$

\section{Diagram 1b}

\section{Set (v). Miscellaneous, centrosymmetric--> highly distorted}

41 to 46 form a miscellaneous group of distorted structures with further distinctive features. Structure $\mathbf{4 1}$ falls into the Set (i) formula category, and T3 shows a planar inner azine moiety, but T1 and T5 are both large $\left(-34^{\circ}, 34^{\circ}\right)$ and conrotatory, and the $o$-nitro substituents are out of plane. The appearance is unique; contrast B. 42 (the $C_{a z i n e} M e$ analogue of 41) and $\mathbf{4 3}$ are configurational isomers, and form an $E, E$ and $E, Z$ pair; steric interaction of the nitro groups with $\mathrm{N}$ lone-pairs causes aryl-ring twist in $\mathbf{4 2}$, and results in configurational change in $\mathbf{4 3}$. The major consequence is a $180^{\circ}$ rotational difference (T4). The other parameters of 42 and 43 differ little apart from T5 (-38 and $66^{\circ}$ respectively). Structures 44 (benzophenone azine) to $\mathbf{4 6}$ resemble 4-bladed propellers on account of the exceptionally bulky nature of $\mathrm{X}$ in the systems [PhCX=N-]-2. For 44 A1 and A4 are large $\left(124^{\circ}\right)$, while for 46 they are different $\left(112^{\circ}\right.$ and $\left.123^{\circ}\right)$. The T4 values recorded for 44 to 46

are $10^{\circ}, 173^{\circ}$ and $-3^{\circ}$ which are identical (or nearly so) to T2. 41, 45 and 46 are formulated in Diagram 1c. 
Table 5

\begin{tabular}{llllllllll}
\hline Molecule $^{\text {Ref }}$ & $\mathrm{N}-\mathrm{N} / \AA$ & $\mathrm{T} 3$ & $\mathrm{~T} 1$ & $\mathrm{~T} 5$ & Remarks & $\mathrm{R} 1$ & $\mathrm{R} 2$ & $\mathrm{~A} 1 /^{\circ}$ & $\mathrm{A} 2 /^{\circ}$ \\
\hline $\mathbf{4 1}^{30}$ & 1.424 & 0 & -34 & 34 & $a$ & $o-\mathrm{NO}_{2}$ & $o-\mathrm{NO}_{2}$ & 120 & 111 \\
$\mathbf{4 2}^{30}$ & 1.420 & 0 & 38 & -38 & $b$ & $\cdots$ & $\cdots$ & 115 & 112 \\
$\mathbf{4 3}^{30}$ & 1.418 & -14 & 37 & 66 & $c$ & & & \\
$\mathbf{4 4}^{31}$ & 1.402 & 47 & 58 & 58 & $d$ & $\mathrm{H}$ & $\mathrm{H}$ & 116 & 114 \\
$\mathbf{4 5}^{32}$ & 1.384 & 57 & 29 & 29 & $e$ & $\mathrm{f}$ & $\mathrm{f}$ & 118 & 118 \\
$\mathbf{4 6}^{26}$ & 1.395 & -53 & -50 & -84 & $g$ & $\mathrm{C}_{\mathrm{az}} \mathrm{C}$ & $\mathrm{C}_{\mathrm{az}} \mathrm{C}$ & 112 & 118 \\
& & & & & & $\mathrm{Cl}_{2} \mathrm{Me}$ & $\mathrm{Cl}_{2} \mathrm{Me}$ & & \\
\hline
\end{tabular}

$a$ Azine carbons ArCH=.

$b$ Azine carbons ArCMe=. The Me group in place of $\mathrm{H}$ has a minimal effect on $\mathrm{T} 1$ and $\mathrm{T} 5$.

$c$ Configurational isomer of 42, being $E, Z$; the $o-\mathrm{NO}_{2}$ conflicting with the $\mathrm{N}$ lone pair is sufficient, in one half of the molecule, to cause exchange of the Me and Ar positions. T5 very large and A1not=A4 $\left(126^{\circ}\right)$.

$d$ Large bulk of phenyl groups on azine carbons contributes to large torsion angles as seen, including $\mathrm{T} 2=\mathrm{T} 4$ at $10^{\circ}$, and inter-bond angles $\mathrm{A} 1=\mathrm{A} 4=124^{\circ}$. Result: four non-parallel ring planes distributed in space.

$e$ Resembles 44 in overall shape. $\mathrm{T} 2=\mathrm{T} 4=7^{\circ}$.

$f$ 2-Pyridyl groups instead of phenyl.

$g$ A1 and A4 differ, $112^{\circ}$ and $123^{\circ}$. R1=R2=H.<smiles>O=[N+]([O-])c1ccccc1/C=N/N=C/c1ccccc1[N+](=O)[O-]</smiles><smiles>CC(Cl)(Cl)/C(=N\N=C(/c1ccccc1)C(C)(Cl)Cl)c1ccccc1</smiles>

\section{Diagram 1c}




\section{Summary}

The factors influencing the sometimes very large deviations from planarity of azines were given at length, but generalisations regarding steric hindrance and conjugative effects are not easy, nor can the magnitude of the packing effect be quantified, in any particular case. It is difficult to assess the role of $p$-substituents whenever opposing effects may operate, typically when -OR groups are involved. Whereas there is an e-attracting influence due to the electronegativity of $\mathrm{O}$ relative to the ring carbon, the chemical, as opposed to static, effect is e-releasing into the ring by the resonance effect. Similarly with $-\mathrm{NR}_{2}$, and in both instances e-withdrawing or e-releasing $\mathrm{R}$ complicates the issue.

T3, which indicates the extent of independence (cf. Ref.15) of the two halves, and the values of T1 and T5 which show torsion about the bond from azine carbon to aromatic ring, are the most critical determinants of structure of an azine molecule in the crystalline state. As to the interbond angles A1 and A2 the overall averages are $118^{\circ}$ and $114^{\circ}$ but the scatter is $+-6^{\circ}$, with occasional differences between these values and those for the other half of the azine molecule (A4 and A3). An extreme case of this effect appears in 33, A1 and its counterpart A4 measuring $115^{\circ}$ and $123^{\circ}$ (unsymmetrical $p$-substitution, OMe and OCN, and azine CMe and CH, respectively); compare 34 and 35. Torsion angles T2 and T4 are generally very similar, indicating co-planarity at the double bonds. A divergence in this respect is shown in the molecule 31, an $\mathrm{X}=\mathrm{Me}$ case, T4 being equal to $6^{\circ}$ adjacent to the $p$-OMe substituted aromatic ring, and $\mathrm{T} 2=1^{\circ}$ where the substituent is $\mathrm{Br}$. Curiously, when 18 and 25 are compared, it is the dibromo compound that has T4 distorted (see Tables 2 and 3). Of course when $\mathrm{X}=\mathrm{Ph}, \mathrm{T} 2$ and T4 values are both much larger, $10^{\circ}$ for $\mathbf{4 4}$ and $7^{\circ}$ for 45; with $\mathrm{X}$ being $\mathrm{CCl}_{2} \mathrm{Me}, \mathrm{T} 2$ is $-5^{\circ}$ and $\mathrm{T} 4$ is $-3^{\mathrm{o}}$. Melting points, and a comparison of structures with those of di-aryl butadienes, might be topics that correlate with these findings. NMR correlations are complementary ${ }^{15}$, and, being solution-based, offset crystal packing effects. Six diagrams of the 46 printed in full in Ref. 4 are appended as Diagram 2 above to illustrate structural diversity among azines; these, given in order of increasing complexity, show in addition to the number given to the molecule (7, 22, 29 etc.), its code letters (SALIAZ, etc.), formula, R factor, and numbered references $(7,5,8$, etc.). The views of the molecules in boxes lettered A, B and C in each lower left-hand corner show (A) conventional formulae, (B) stereo diagrams with atomic nomenclature, and (C) stereo diagrams orthogonal to those in $\mathrm{B}$. 


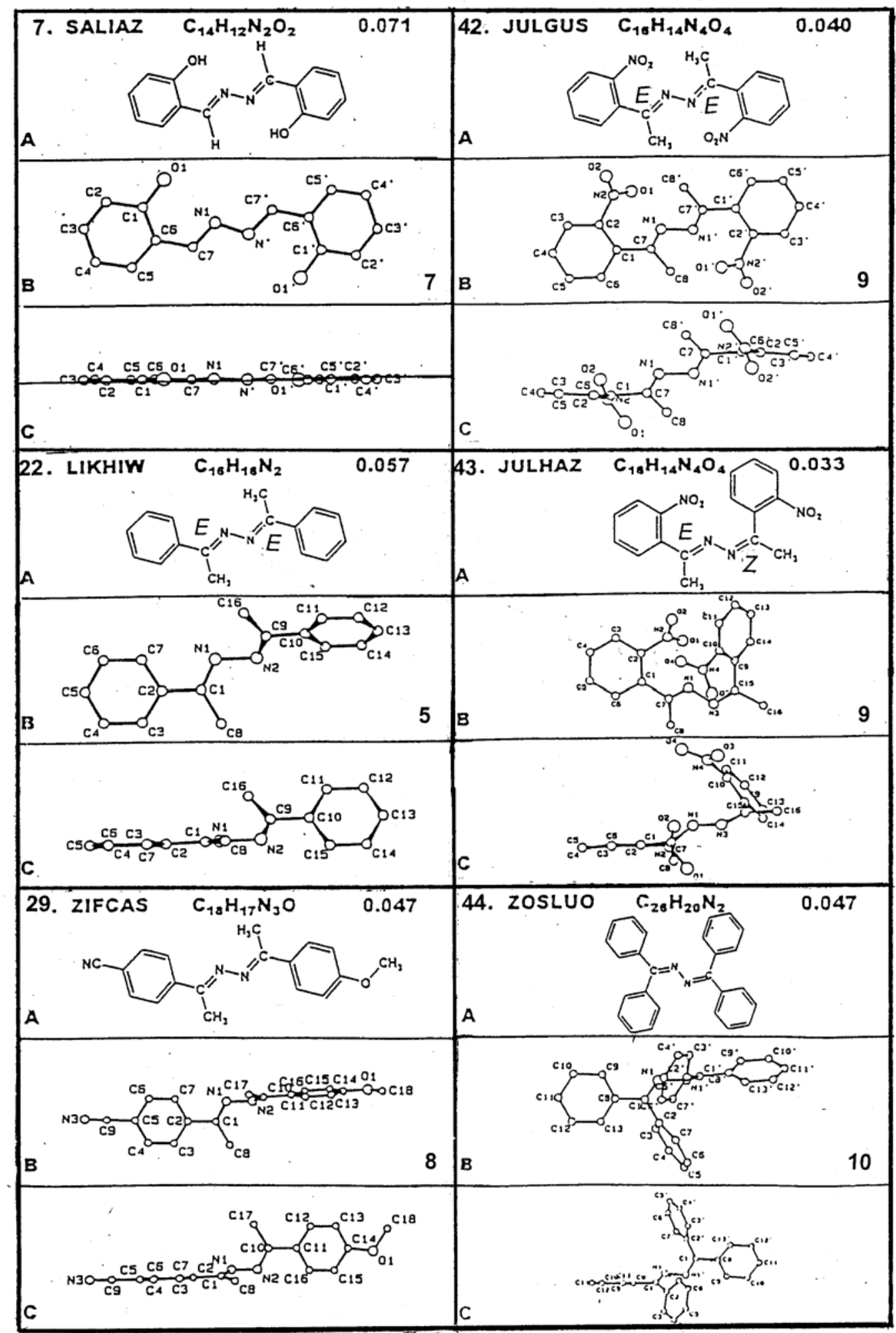

Diagram 2

Key to lettering and numbering are given in text 


\section{Experimental Section}

The method of preparation and x-ray crystallographic examination of $\mathbf{A}$ and $\mathbf{B}$ were reported briefly, and stereo diagrams indicating their $Z, E$ and $E, E$ conformations were given ${ }^{1}$. Details for A, C, D and E follow.

Structure A. $\left[\mathrm{C}_{15} \mathrm{H}_{15} \mathrm{~N}_{2} \mathrm{O}_{2}\right]^{+} . \mathrm{Cl}^{-} \quad P 2_{1} / c, \quad Z=4, \quad a=7.967(1) \quad b=6.044(1) \quad c=29.407(2) \mathrm{A}$, $\beta=95.60(4)^{\circ}$

$\mathrm{X}$-ray diffraction showed that the crystal belonged to the monoclinic system (2/m Laue symmetry). The space group is $\mathrm{P} 2_{1} / \mathrm{c}$, from the following conditions: hkl : none; h0l : l = 2n; $0 \mathrm{k} 0: \mathrm{k}=2 \mathrm{n}$.

Density and unit cell volume indicated four formula units in the unit cell; direct methods were used to solve the structure. Careful inspection of the x-ray reflections of the crystal, mounted about the b-axis, showed that the crystal was twinned, and the structure obtained was an average one. Refinement did not yield an R factor of better than 0.145. (Evidence of twinning was obtained also for the fluoride, bromide and iodide analogues of the chloride A). Figure 1 displays (a) the perspective view, with atomic nomenclature, of $\mathbf{A} ;(b)$ the stereo diagram; and (c) a view of the cation with r.m.s.(root mean square) ring plane A perpendicular. Figure 2 shows (a) a packing diagram for $\mathbf{A}$ viewed along [010], and (b) its stereo diagram

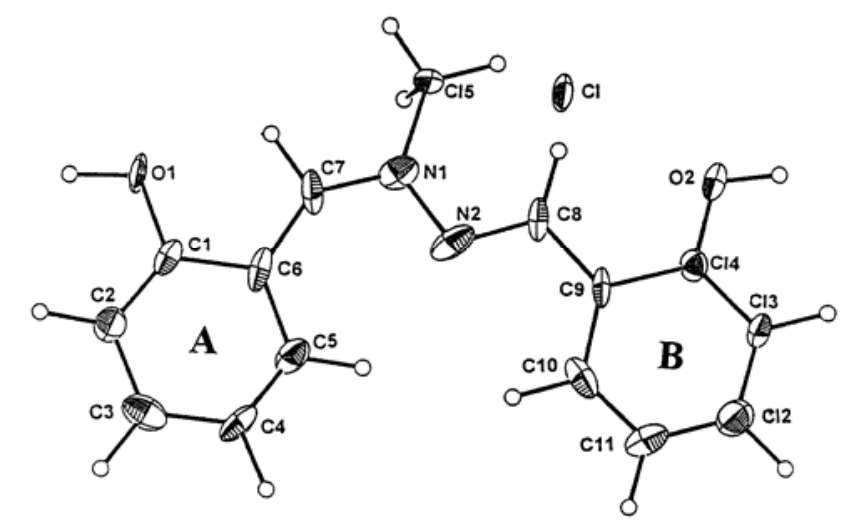

(a)

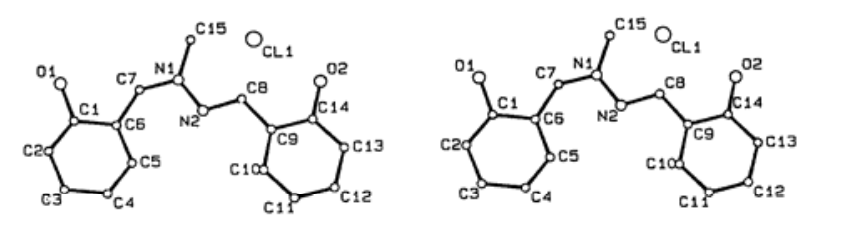

(b)

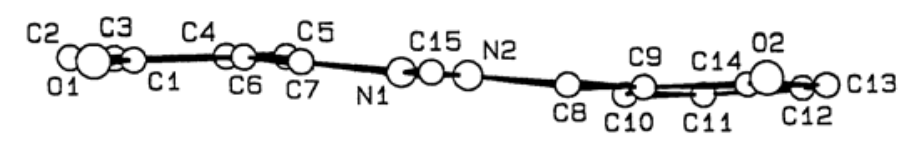

(c)

\section{Figure 1}




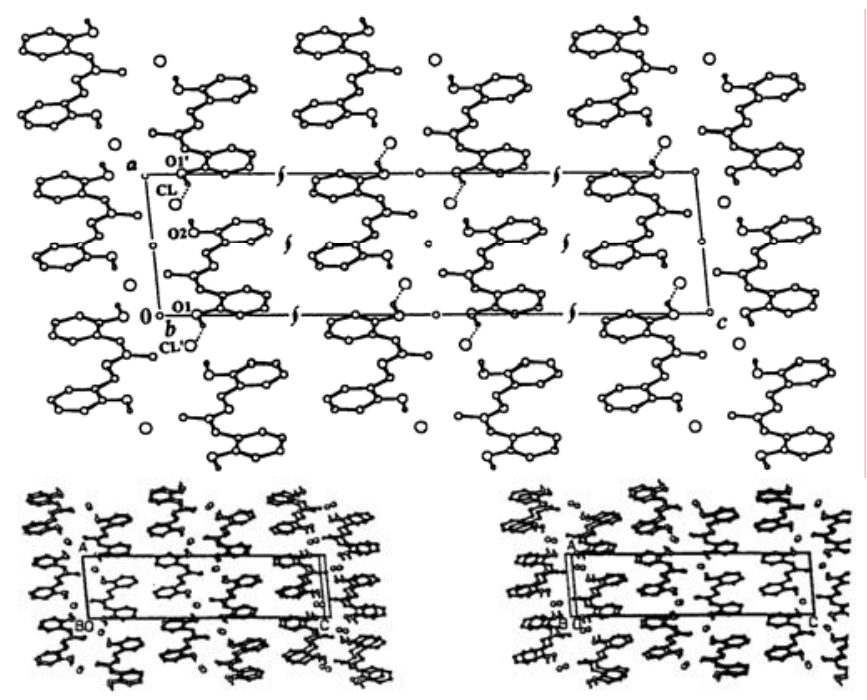

(a)

Figure 2

The dihedral angle between the r.m.s. planes of rings $\mathrm{A}$ and $\mathrm{B}$ is $4.1(2)^{\mathrm{o}}$; the r.m.s. deviation of the ring atoms is $0.01 \AA$; the angles between the r.m.s.

Planes of the azine system and those of $\mathrm{A}$ and $\mathrm{B}$ are $5.3(2)^{\circ}$ and $7.5(3)^{\circ}$, respectively; and the torsion angleT3 is $180^{\circ}$. Table 6 gives parameters for the two intermolecular hydrogen bonds that alternate between two oxygen and two chlorine atoms as the Figure shows. The two (nearly) coplanar phenyl rings are kept in place, parallel to the $c$ axis, by two hydrogen bonds. Alternate planes of the rings are inclined at angles of approximately $60^{\circ}$.

Table 6

\begin{tabular}{|c|c|c|c|c|c|}
\hline \multicolumn{2}{|l|}{ Bond } & \multicolumn{3}{|c|}{ Distance $(\AA)$} & \multirow{2}{*}{$\frac{\text { Angle }\left(\mathrm{A}^{0}\right)}{\mathrm{D}-\mathrm{H} \ldots . . \mathrm{A}}$} \\
\hline $\mathrm{H}$ & & $\mathrm{D}-\mathrm{H}$ & H.....A & D....A & \\
\hline $\mathrm{O}(1)-\mathrm{H}(1 \mathrm{O}) \ldots . . \mathrm{Cl}(1)$ & $(a)$ & 0.97 & 2.25 & $2.950(7)$ & $124(1)$ \\
\hline $\mathrm{O}(2)-\mathrm{H}(2 \mathrm{O}) \ldots \mathrm{Cl}(1)$ & (b) & 0.97 & 2.03 & $2.979(8)$ & 164(1) \\
\hline \multicolumn{6}{|c|}{ (D=donor, $A=$ acceptor $)$} \\
\hline \multicolumn{6}{|l|}{ Close contacts: } \\
\hline $\mathrm{Cl}(1) \ldots . . \mathrm{H}(152)$ & (c) & 2.62 & & & \\
\hline $\mathrm{H}(2 \mathrm{O}) \ldots . . . \mathrm{H}(152)$ & (d) & 2.29 & & & \\
\hline $\begin{array}{l}\text { Equivalent positions } \\
x-1, y+1, z \text { (b) } x, y-1, z\end{array}$ & $-x$ & $-y$, & $z(d)-x$ & $-y,-z$ & \\
\hline
\end{tabular}


Structure C. $\left[\mathrm{C}_{15} \mathrm{H}_{15} \mathrm{~N}_{2} \mathrm{O}_{2}\right]^{+} . \mathrm{Cl} \quad \mathrm{P2}{ }_{1} / n, \quad Z=4, \quad a=6.657(1) \quad b=16.134(1) \quad c=13.608(2) \AA$, $\beta=99.94(3)^{\circ}$

X-ray diffraction showed that the crystal belonged to the monoclinic system (2/m Laue symmetry). The space group is $\mathrm{P} 21 / n$, from the conditions limiting reflections

$$
\begin{gathered}
h k l: \text { none } \\
h 0 l: \mathrm{h}+\mathrm{l}=2 \mathrm{n} \\
0 k 0: \mathrm{k}=2 \mathrm{n}
\end{gathered}
$$

Unit cell and density measurements indicated $Z=4$, and hence the formula unit was placed in a general position. Direct methods were used to solve the crystal structure; R factor 0.093. Figure 3 gives (a) the perspective view of $\mathbf{C}$, (b) its stereo diagram and (c) a view of the cation with r.m.s. plane A perpendicular. Figure 4 shows (a) the packing diagram of $\mathbf{C}$, with hydrogen bonds, along [100\}; and (b) its stereo diagram along [100]. Figure 5 displays stereo diagrams of C (a) along [010] and (b) [001].

The general structure of $\mathbf{C}$ resembles that of $\mathbf{A}$, both having the atypical $Z, E$ configuration. The dihedral angle between the least-squares planes through $\mathbf{A}$ and $\mathbf{B}$ is $8.4(3)^{\circ}$, and the r.m.s. deviations of the ring atoms is $0.01 \AA$. Dihedral angles between the mean plane of the azine system and planes A and B are $7.5(2)^{\circ}$ and $5.0(3)^{\circ}$, and the torsion angle T3 is $179.0(7)^{\circ}$. The chelated ring formed by the relatively weak hydrogen bond $\mathrm{C}(5)-\mathrm{H}(5) \ldots . . . \mathrm{N}(2)$ is nearly flat [maximum deviation $0.22 \AA$, for $\mathrm{N}(2)$ ]. One relatively strong inter-ionic $\mathrm{H}$ bond [Table 7, entry $(a)$ ] gives stability to the structure.

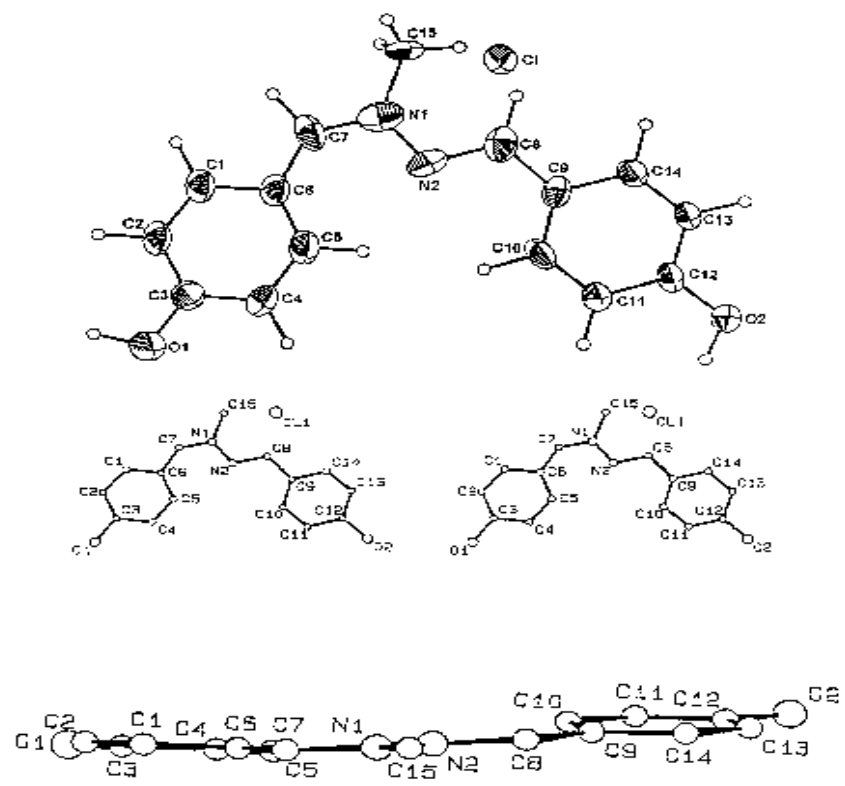

Figure 3 


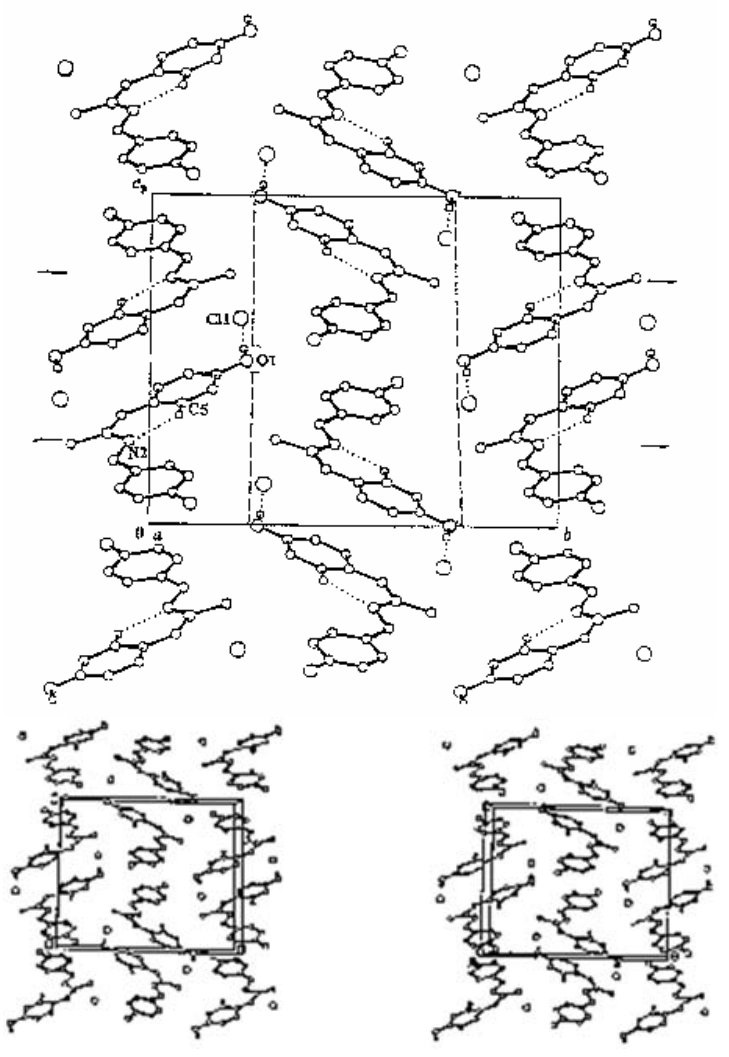

Figure 4
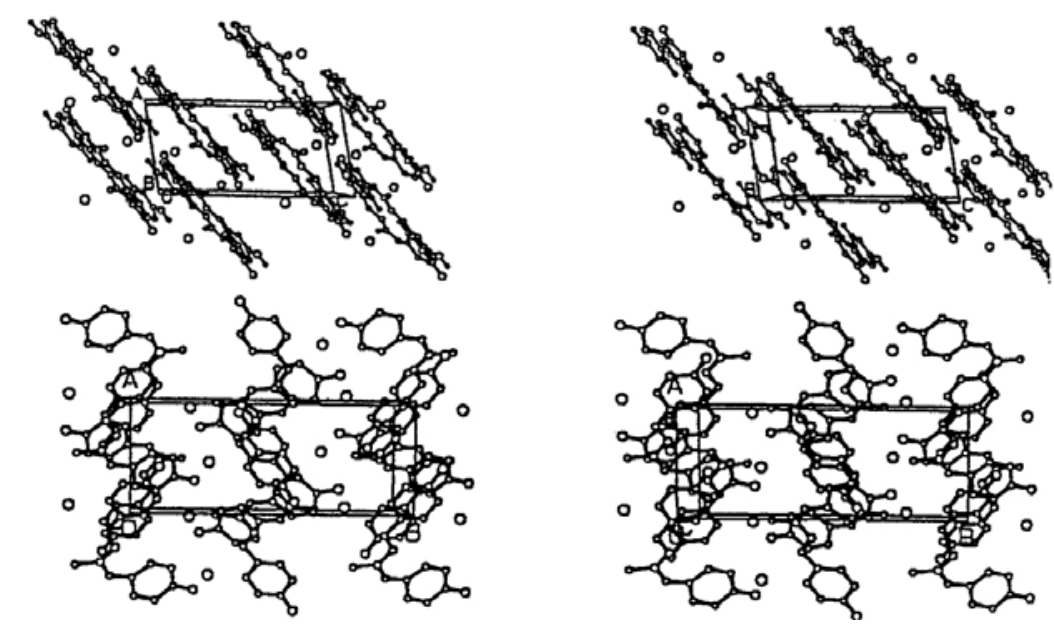

(a)

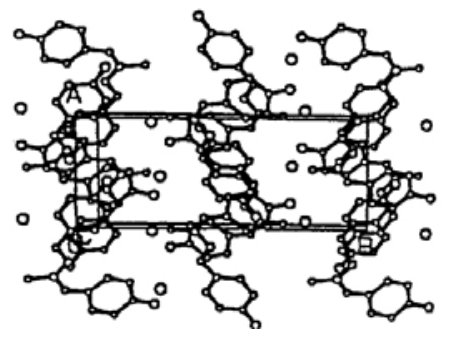

(b)

Figure 5 
Table 7

\begin{tabular}{|c|c|c|c|c|c|}
\hline \multicolumn{2}{|l|}{ Bond } & \multicolumn{3}{|c|}{ Distance $(\AA)$} & \multirow{2}{*}{$\frac{\text { Angle }\left(\mathrm{A}^{0}\right)}{\text { D-H.....A }}$} \\
\hline $\mathrm{D} \quad \mathrm{H}$ & & D-H & H.....A & D....A & \\
\hline $\mathrm{C}(5)-\mathrm{H}(5) \ldots \ldots \mathrm{N}(2)$ & & 1.10 & 2.19 & $2.907(12)$ & 121(3) \\
\hline $\mathrm{O}(1)-\mathrm{H}(1 \mathrm{O}) \ldots \mathrm{Cl}(1)$ & (a) & 0.97 & 2.07 & $3.039(8)$ & $176(5)$ \\
\hline \multicolumn{6}{|c|}{ (D=donor, $\mathrm{A}=$ =acceptor) } \\
\hline \multicolumn{6}{|l|}{ Close contacts: } \\
\hline $\mathrm{Cl}(1) \ldots . . \mathrm{H}(10)$ & (b) & 2.07 & & & \\
\hline $\mathrm{Cl}(1) \ldots . . \mathrm{H}(2)$ & (d) & 2.78 & & & \\
\hline \multicolumn{6}{|c|}{ Equivalent positions: } \\
\hline
\end{tabular}

Structure D. $\mathrm{C}_{14} \mathrm{H}_{12} \mathrm{~N}_{2} \mathrm{O}_{2} \mathrm{P} 2_{1} / n, Z=4, a=12.605(1), b=8.670(1), c=12.005(1) A, \beta=115.16(2)^{o}$ X-ray diffraction showed that the crystal belonged to the monoclinic system $(2 / \mathrm{m}$ Laue symmetry). The space group is $\mathrm{P} 21 / n$, from the conditions limiting reflections

$$
\begin{gathered}
h k l: \text { none } \\
h 0 l: \mathrm{h}+\mathrm{l}=2 \mathrm{n} \\
0 k 0: \mathrm{k}=2 \mathrm{n}
\end{gathered}
$$

Unit cell and density measurements indicated $Z=4$, and hence the formula unit was placed in a general position. Direct methods were used to solve the crystal structure ( $R$ factor=0.043). These data resemble those for $\mathbf{C}$. Figure 6 gives (a) the perspective view of $\mathbf{D}$, (b) the stereo diagram and (c) a view of the cation with r.m.s. plane A perpendicular. Figure 7 shows (a) the packing diagram of $\mathbf{D}$, with one intermolecular hydrogen bond, along [001\}; and (b) its stereo diagram. Figure 8 displays stereo packing diagrams of $\mathbf{D}$ along (a) [100] and (b) [010]. 


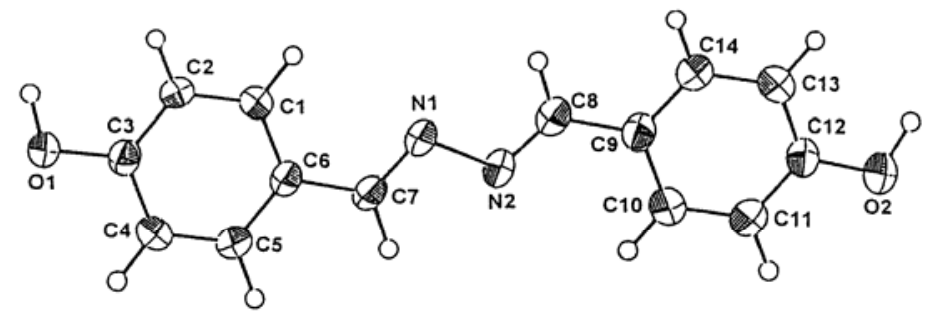

(a)

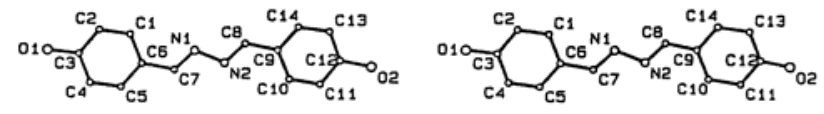

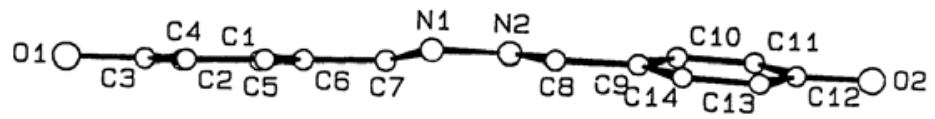

Figure 6

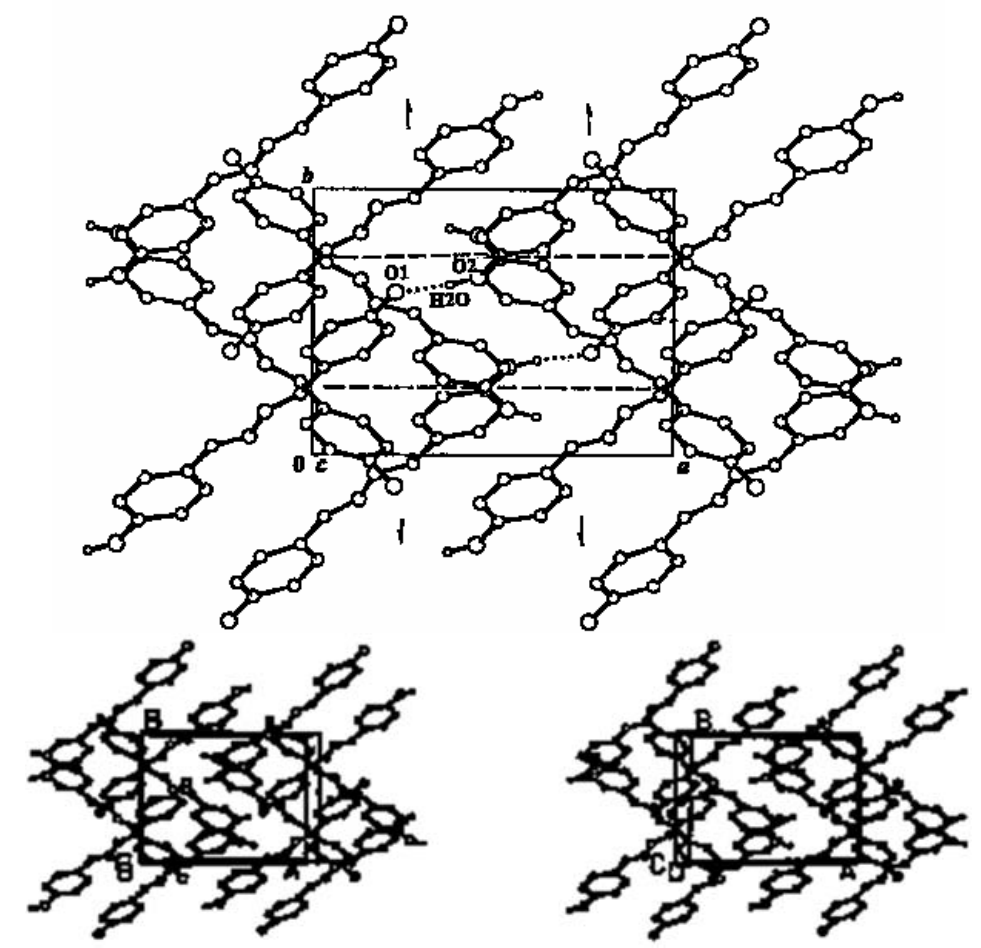

(a)

(b)

Figure 7 

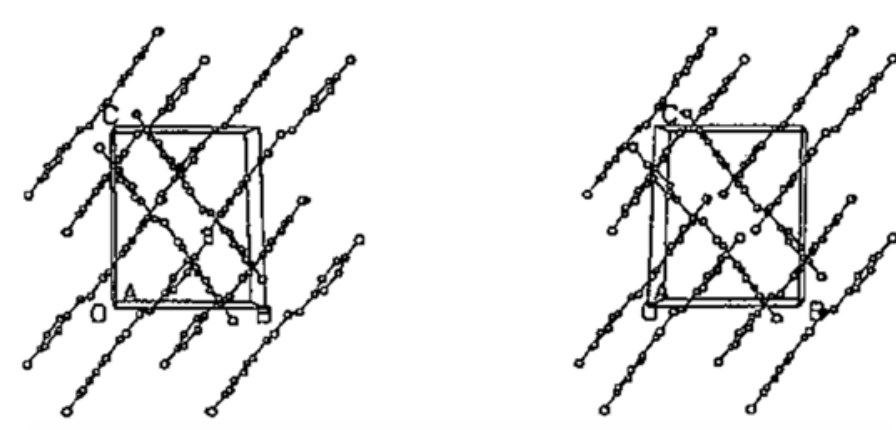

(a)
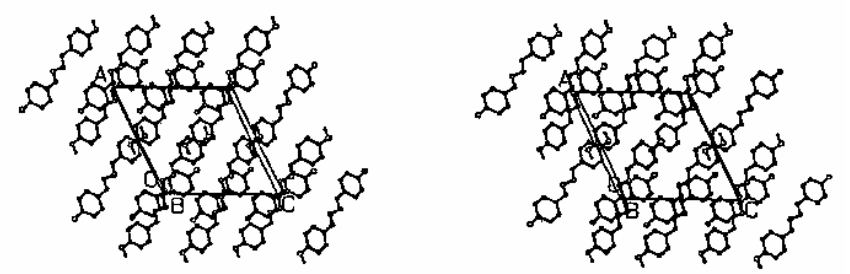

(b)

\section{Figure 8}

The formula unit of $\mathbf{D}$ resembles that of $\mathbf{B}$ in having the $\mathrm{E}$ configuration at both $\mathrm{C}=\mathrm{N}$ bonds in the azine chain. $\mathbf{D}$, however, lacks centro-symmetry. The dihedral angle between the r.m.s. planes (A and B) of the two aryl rings is $9.5(1)^{\circ}$. The angles between the r.m.s. plane of the azine system and those of $A$ and $B$ are $-4.5(1)^{\circ}$ and $13.5(1)^{\circ}$ respectively. Due to noticeable kinks in the azine system (Figure 6 (c)) the torsion angle about N-N is $165.6(2)^{\circ}$. Among other nonsymmetric structures having relatively small angular differences between A and B planes, yet showing very diverse molecular formulae, are 2, 5, 8, 20, 33 and 34.

From the packing diagram (Figure 8 (a)) it is evident that the planes of molecules of $\mathbf{D}$ lie approximately perpendicular to the $b / c$ plane, and in alternate directions approximately parallel to the two diagonals of the $b-c$ plane. Distances between the molecular planes alternate between

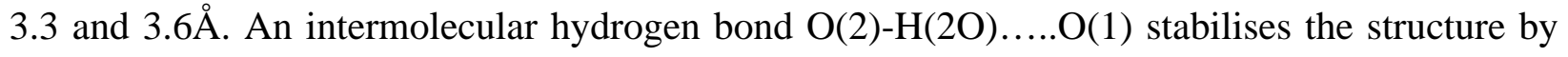
interconnecting the molecules along their linear axes. Table 8 records data for the H-bond.

Table 8

\begin{tabular}{ccccc}
\hline Bond & \multicolumn{3}{c}{ Distance $(\AA)$} & Angle $\left(\mathrm{A}^{0}\right)$ \\
\hline $\mathrm{D}$ H A & $\mathrm{D}-\mathrm{H}$ & $\mathrm{H} \ldots . \mathrm{A}$ & $\mathrm{D} \ldots . . \mathrm{A}$ & $\mathrm{D}-\mathrm{H} \ldots . . \mathrm{A}$ \\
$\mathrm{O}(2)-\mathrm{H}(2 \mathrm{O}) \ldots \mathrm{O}(1)$ & 0.97 & 1.78 & $2.764(3)$ & $173(2)$ \\
& & & & \\
(D=donor, $\mathrm{A}=$ =acceptor $)$ & & & & \\
No close contacts observed & & & \\
& & & & \\
Equivalent positions: & & & & \\
(a) $x-1, y-1, z-1$ &
\end{tabular}


Structure E. $C_{16} H_{6} N_{2} \quad P 2_{1} / n, \quad Z=4, \quad a=11.709(2), \quad b=7.552(1), c=14.874(4) \AA, \quad \beta=97.76(3)^{o}$ $X$-ray diffraction indicated that the crystal belonged to the monoclinic system $(2 / \mathrm{m}$ Laue symmetry). The space group is $\mathrm{P} 2_{1} / n$, from the conditions limiting reflections

$$
\begin{gathered}
h k l: \text { none } \\
h 0 l: \mathrm{h}+\mathrm{l}=2 \mathrm{n} \\
0 k 0: \mathrm{k}=2 \mathrm{n}
\end{gathered}
$$

Unit cell and density determinations fixed $\mathrm{Z}=4$, and the formula unit of $\mathbf{E}$ is placed at a general position. Direct methods for structure determination gave an E-map showing some of the non-hydrogen atoms of two formula units overlapping, with one unit shifted by a distance of one half of a phenyl ring along the axis of the azine (Figure 9; projection down $b$ axis). Refinement procedures did not help, but the structure was eventually solved by using the average positions of the two displaced molecules (R factor 0.046). Figure 10 shows (a) perspective and (b) stereo diagrams, and two views (c) and (d) of $\mathbf{E}$, drawn with each of its r.m.s. ring planes $\mathrm{A}$ and $\mathrm{B}$ perpendicular. Figure 11 shows (a) the packing diagram of $\mathbf{E}$ viewed along [010], and (b) its stereo diagram. Figure 12 shows stereo views of the packing diagram along (a) [100] and (b) [001].

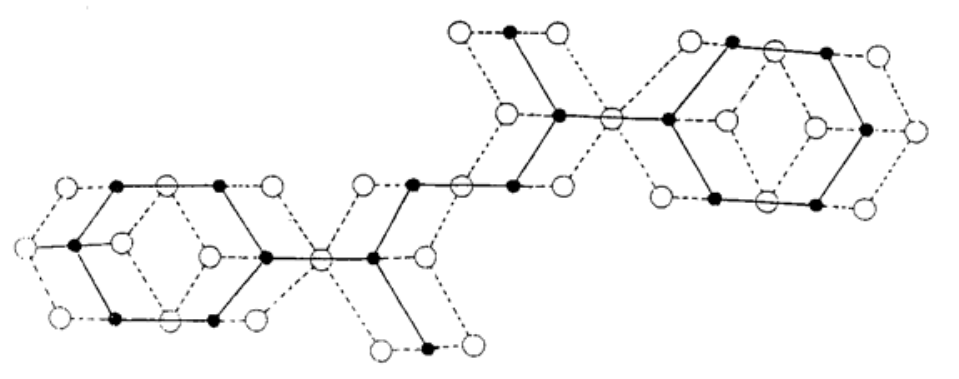

Figure 9 

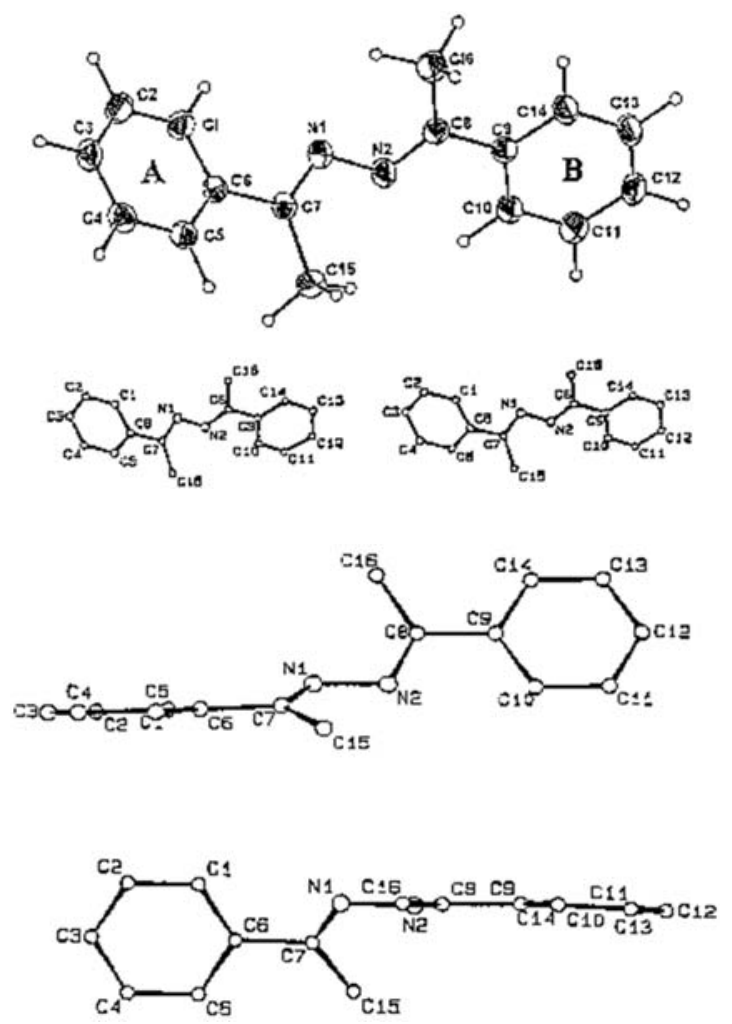

Figure 10

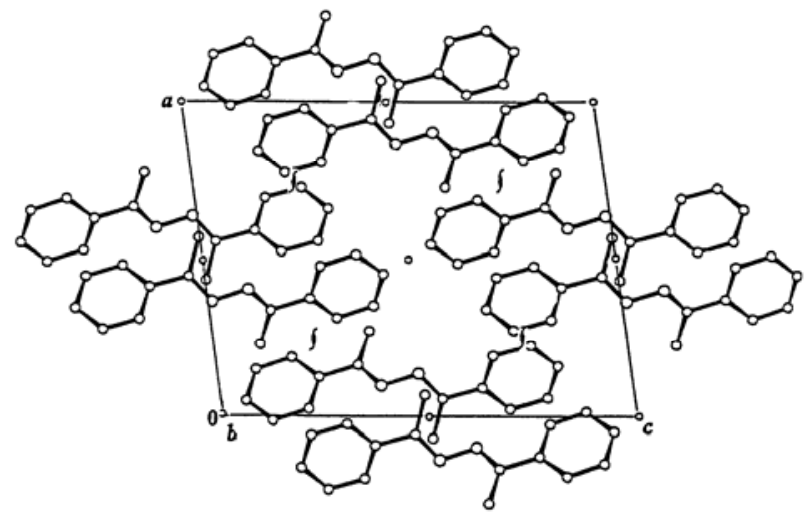

(a)
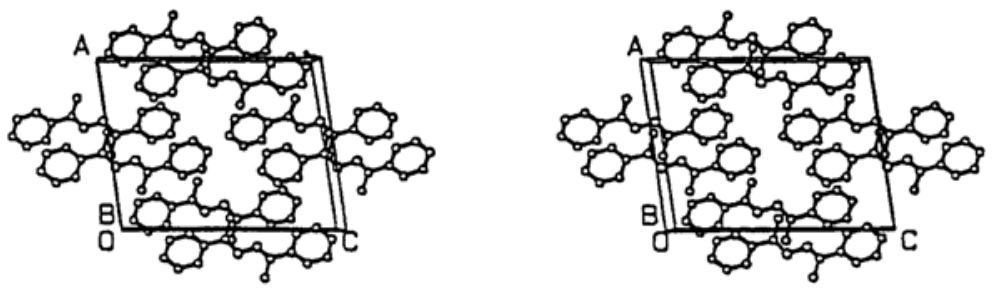

(b)

Figure 11 

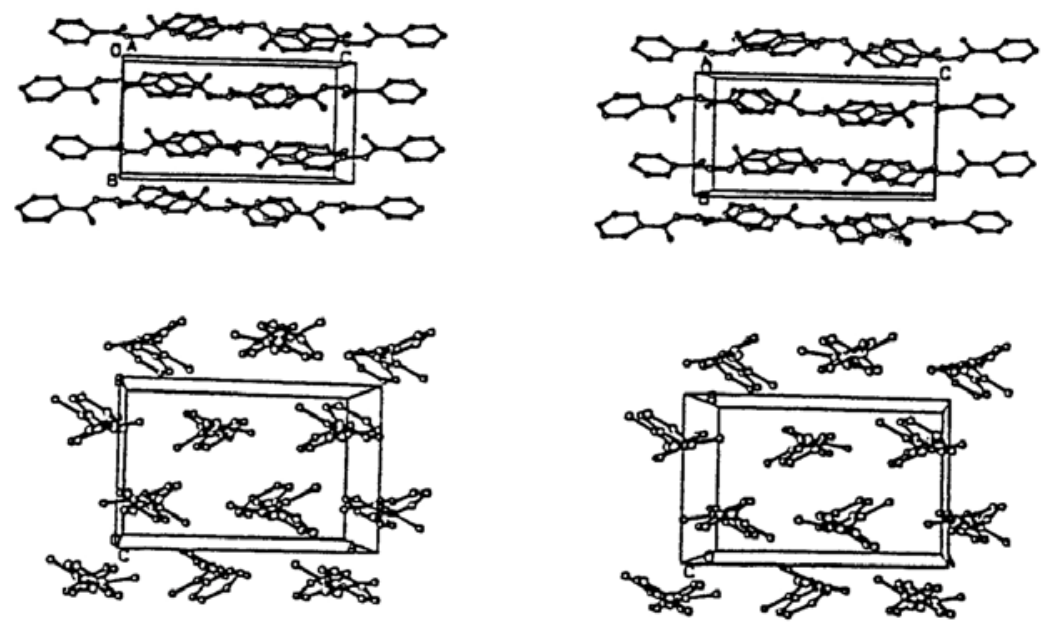

\section{Figure 12}

The molecule $(E, E)$ does not contain a centre of symmetry, but has the torsion angle $\mathrm{C}(7)=\mathrm{N}(1)-\mathrm{N}(2)=\mathrm{C}(8)$ equal to $-139.2(2)^{\circ}$. In this and other structural parameters there is good correlation with a published result ${ }^{5}$.

\section{Acknowledgments}

This paper is largely based on the Ph.D. thesis of the late Professor T.G.D.van Schalkwyk. Thanks are due to the J. Murray Hofmeyr Charitable Trust for providing financial assistance, and to Professors L.R.Nassimbeni and M.R.Caira for many helpful discussions. Dr Neil Ravenscroft and Mr Vincent Smith helped in the presentation of this paper.

\section{References}

1. Stephen, A. M.; vanSchalkwyk, T. G. D.; Ravenscroft, N. ARKIVOC 2002,103.

2. Teoh, S.-G.; Teo, S.-B.; Yeap, G.-Y.; Fun, H.-K. Main Group Met. Chem. 1994, 17, 595; Chem. Abstr. 1994, 122, 80804.

3. Lewis, M.; Glaser, R. J. Org. Chem. 2002, 67, 1441.

4. van Schalkwyk, T. G. D. Ph.D. Thesis, University of Cape Town, 2001.

5. Burke-Laing, M. and Laing, M. Acta Cryst. B 1976, 32, 3216.

6. Noltemeyer, M.; Schmidt, M.; Sheldrick, G. M. Z. Kristallogr. 1983, 163, 129.

7. Marignan, J.; Galigne, J. L.; Falgueirettes, J. Acta Cryst. B 1972, 28 , 93.

8. Astheimer, H.; Walz, L.; Haase, W.; Loub, J.; Muller, H. J.; Gallardo, M. Mol. Cryst. Liq. Cryst. 1985, 131, 343.

9. $\quad$ Centore, R.; Panunzi, B.; Tuzi, A. Z. Kristallografiya 1996, 211, 31. 
10. Arcovito, G.; Bonamico, M.; Domenicano, A.; Vaciago, A. J. Chem. Soc. B 1969, 733.

11. Chen, W.; Liu, C.-M.; Li, D.-G.; You, X.-Z. Acta Cryst. C 1997, 53, 1499.

12. Sereda, S. V.; Antipin, M. Yu.; Timofeeva, T. V.; Struchkov, Yu. T. Kristallografiya 1988, 33,118 .

13. Sereda, S. V.; Shelyazhenko, S. V.; Fialkov, Yu. A.; Pivovarova, N. S; Mikhalik, V. A. Kristallografiya 1992, 37, 894.

14. Fayos, J.; Martinez-Ripoll, M.; Garcia-Mina, M. C.; Gonzalez-Martinez, J.; Arrese, F. Acta Cryst. B 1980, 36, 1952.

15. Chen, G. S.; Anthamatten, M.; Barnes, C. L.; Glaser, R. J. Org. Chem. 1994, 59, 4336.

16. Glaser, R.; Chen, G. S.; Anthamatten, M.; Barnes, C. L. J. Chem. Soc., Perkin Trans. 2 1995, 1449.

17. Ciajolo, M. R.; Sirigu, A.; Tuzi, A. Acta Cryst. C 1985, 41, 483.

18. Chen, G. S.; Anthamatten, M.; Barnes, C. L.; Glaser, R. Angew. Chem., Int. Ed. 1994, 33, 1081.

19. Garcia-Mina, M. C.; Arrese, F.; Martinez-Ripoll, M.; Garcia-Blanco, S.; Serrano, J. L. Acta Cryst. B 1982, 38, 2726.

20. Centore, R.; Ciajolo, M. R.; Roviello, A.; Sirigu, A.; Tuzi, A. Mol. Cryst. Liq. Cryst. 1990, 165, 99.

21. Chen, G. S.; Wilbur, J. K.; Barnes, C. L.; Glaser, R. J. Chem. Soc. Perkin Trans. 2 1995, 2311.

22. Lewis, M.; Barnes, C. L.; Glaser, R. Can. J. Chem. 1998, 76, 1371.

23. Lewis, M.; Barnes, C. L.; Glaser, R. J. Chem. Crystallog. 1999, 29, 1043.

24. Centore, R.; Garzillo, C. J. Chem. Soc., Perkin Trans. 2 1997, 79.

25. de Meester, P.; Chu, S. S. C.; Johnson, J. E. Acta Cryst. C 1986, 42, 1657.

26. Lai, E. C. K.; Mackay, D.; Taylor, N. J.; Watson, K. N. Can J. Chem. 1988, 66, 2839.

27. Glaser, R.; Chen, G. S.; Barnes, C. L. J. Org. Chem. 1993, 58, 7446.

28. Dehne, H.; Drexler, K.; Scheunemann, A.; Reinke, H.; Michalik, M. Phosphorus, Sulfur, Silicon, Related Elem. 1996, 118, 79.

29. Xu, Z.; Thompson, L. K.; Miller, D. O. Inorg. Chem. 1997, 36, 3985.

30. Hsu, L.-Y.; Nordman, C. E.; Kenny, D. H. Acta Cryst. C 1993, 49, 398.

31. Saha, A. K.; Hossain, M. M.; Grubisha, D. S.; Bennett, D. W. J. Chem. Cryst. 1995, 25, 383.

32. Amadei, S.; Garcelli, M., Ianelli, S.; Cozzini, P.; Pelagatti, P.; Pelizzi, C. J. Chem. Soc. Dalton Trans. 1998, 1025. 